\title{
Role of Cardiorespiratory Fitness on the Association Between Physical Activity and Abdominal Fat Content in Adolescents: The HELENA Study
}

\author{
Authors \\ V. España-Romero ${ }^{1,2,3}$, F. B. Ortega ${ }^{1,2}$, J. R. Ruiz ${ }^{2}$, E. G. Artero ${ }^{1}$, D. Martínez-Gómez ${ }^{4}$, G. Vicente- \\ Rodriguez $^{5 a, b}$, D. Moliner-Urdiales ${ }^{5 a, b}$, L. Gracia-Marco ${ }^{5 a, c}$, D. Ciarapica ${ }^{6}$, K. Widhalm , M. J. Castillo \\ Garzon' ${ }^{1}$ M. Sjöstrom ${ }^{2}$, L. A. Moreno ${ }^{5, c}$
}

Affiliations

Affiliation addresses are listed at the end of the article
Key words

- abdominal fat content

- adolescents

- cardiorespiratory fitness

- physical activity accepted after revision

June 05, 2010

\section{Bibliography}

DOI http://dx.doi.org/

10.1055/s-0030-1261935

Published online:

July 21, 2010

Int J Sports Med 2010; 31:

679-682 (c) Georg Thieme

Verlag KG Stuttgart · New York

ISSN 0172-4622

Correspondence

Vanesa España-Romero

Department of Medical

Physiology

School of Medicine

University of Granada

Granada

Spain

Tel.: + 34/958/243540

Fax: + 34/958/24 9015

vanespa@ugr.es

\section{Abstract}

$\nabla$

We examined the role of cardiorespiratory fitness (CRF) on the association between physical activity (PA) and abdominal fat content in adolescents. Abdominal fat content was measured by waist circumference, waist-to-height ratio and dual energy X-ray absorptiometry (DXA) at 3 regions ( $R 1, R 2$, and $R 3$ ). PA and CRF were assessed by accelerometry and the $20 \mathrm{~m}$-shuttle run test, respectively. Vigorous PA was inversely associated with waist circumference and waistto-height ratio ( $\beta$ from -0.149 to -0.197 ; $\mathrm{p}<0.05$ ). In both CRF groups (i.e., low and high),

\section{Introduction}

\section{$\nabla$}

Current evidence suggests that abdominal fat content is an independent risk factor for cardiovascular disease $[12,14]$. Abdominal fat content can be measured with reference methods such as nuclear magnetic resonance that allows the assessment of visceral and subcutaneous adipose tissue [2]; dual energy x-ray absorptiometry (DXA) is also emerging as a technique allowing to assess abdominal fat content [15]; or it can also be estimated with field measurements such as waist circumference or waist-to-height ratio [23]. Rapid increases in abdominal fat content among children and adolescents have been reported [12], and the negative consequences on the metabolic health status in youth with an excess of abdominal fat, even for a given weight status, are well-known [10]. Central obesity prevention aiming to reduce abdominal fat content should be a target for intervention to reduce the health risk from the first decades of life.

PA has shown to be negatively associated with markers of abdominal fat content such as waist circumference or waist-to-height ratio [5,22], yet the results are contradictory $[6,21]$. High levels vigorous and moderate-to-vigorous PA (also average PA in the low CRF group) were inversely associated with abdominal fat (i.e., R1, R2 and $\mathrm{R} 3 ; \beta$ from -0.146 to $-0.244 ; \mathrm{p}<0.05$ ). This association did not differ according to CRF group ( $P$ for interaction $>0.05$ ), yet the percentage of variance in abdominal fat content, when assessed by DXA, explained by PA was slightly higher in adolescents with low CRF (3-8\%) compared to those with high CRF (2-4\%). The findings indicate that there is not a clear interaction effect of CRF in the association between PA and abdominal fat in adolescents, yet slightly stronger association was observed in the low fit group.

of cardiorespiratory fitness (CRF) are also associated with lower abdominal fat content in adolescents [24]. Moreover, CRF seems to be an interacting factor in the relationships between PA and other health outcomes such as cardiovascular disease risk factors [7]. In a previous study conducted in Swedish children and adolescents, we found that the association between PA and waist circumference varied according to the CRF levels, with an unexpected positive association between PA and waist circumference in those participants with high CRF [21]. Whether the methodology used to assess abdominal fat content might have influenced these unexpected findings is not known. Therefore, in the present study we examined the role of CRF on the association between PA and abdominal fat content assessed by waist circumference, waist-to-height ratio and DXA at 3 different regions of the abdomen in a Spanish cohort of adolescents participating in the HELENA-CSS (Healthy Lifestyle in Europe by Nutrition in Adolescence Cross-Sectional) study. 


\section{Methods}

$\nabla$

\section{Subjects}

The HELENA-CSS is a multi-centre study performed in adolescents from 10 European cities [16]. All the adolescents meeting the general HELENA inclusion criteria (not participating simultaneously in another clinical trial, free of any acute infection or disease lasting less than 1 week before the inclusion) and with valid data for age, gender and body mass index, were considered the final HELENA-CSS sample: 3528 adolescents aged 12.5 to $17.5 \mathrm{yr}$. An accurate assessment of abdominal adiposity was crucial for the purpose of the current study, so we focused our analyses on the sub-sample from Zaragoza (Spain), in which DXA assessment was carried out. A total of 122 males and 132 females with complete data on waist circumference, accelerometry, 20 m shuttle run test and DXA were included in the analyses. More details about the sampling procedures, preparation of the field teams, pilot study and reliability of the data can be found elsewhere $[16,17,19,20]$. Signed informed consent was obtained from all participants and their parents. The study was performed following the ethical guidelines of the Declaration of Helsinki 1961 (revision of Edinburgh 2000), for the Spanish cohort the protocol was approved by the Research Ethics Committee of the Government of Aragón (CEICA) and it also was performed in accordance with the ethical standards of the International Journal of Sport Medicine [8].

\section{Body fat assessment}

Abdominal fat content was measured by waist circumference and waist-to-height ratio. More details about the anthropometric procedure have been described elsewhere [17]. Moreover, abdominal fat content was also assessed by DXA at 3 different regions $R 1, R 2$, and $R 3$ [11] using a pediatric version of the software QDR-Explorer (Hologic Corp., Software version 12.4, Waltham, MA). For R1, the upper border was established parallel to the end of the lowest rib. The upper border of R2 was parallel to the junction of T12 and L1 vertebrae, and for R3, it was parallel to the middle of T12 vertebrae. More details about the characteristics of this sample and study procedures have been described elsewhere [15].

\section{Physical activity}

A uni-axial accelerometer (Actigraph GT1M, Manufacturing Technology Inc. Pensacola, FL, USA) was used to assess PA [15]. The time spent in moderate PA (3-6 METs) and vigorous PA ( > 6 METs) were calculated based upon cut offs of 2000 and 4000 counts per minute, respectively $[6,18]$. Furthermore, the time spent in moderate-to-vigorous PA (MVPA) was calculated as the sum of moderate and vigorous periods. These cut-offs points to define the intensity categories are similar to those used in previous studies in youth $[6,18]$. Average PA was calculated as the total number of counts divided by the registered time (counts/min).

\section{Cardiorespiratory fitness}

CRF was assessed by the $20 \mathrm{~m}$ shuttle run test. Participants were required to run between 2 lines $20 \mathrm{~m}$ apart, while keeping pace with audio signals emitted from a pre-recorded $\mathrm{CD}$. The initial speed was $8.5 \mathrm{~km} / \mathrm{h}$, and was increased by $0.5 \mathrm{~km} / \mathrm{h}$ per minute ( 1 min equals one stage). More detailed information about the fitness testing protocol can be found elsewhere [19,20].

Based on the $20 \mathrm{~m}$ shuttle run test performance, maximal oxygen consumption $\left(\mathrm{VO}_{2 \max }\right)$ was estimated from Leger's equation [13]. CRF was dichotomised (low/high) using the cut-off values proposed by the FITNESSGRAM [26]. These cut-off values have been proposed by scientists and worldwide recognised organizations to define a healthy CRF level at these ages $[4,26]$.

\section{Statistical analysis}

After square root transformation of moderate PA and vigorous PA, and natural logarithm transformation of height, MVPA, average $\mathrm{PA}, \mathrm{VO}_{2 \mathrm{max}}$ and DXA parameters (R1, R2 and R3), all the residuals showed a satisfactory pattern. Interaction effects (i.e., sex $\times$ main exposures and age $\times$ main exposures) were considered to examine whether age or sex modified the associations between PA and abdominal fat content. Since no interaction was found, all sex and age groups were analysed together. All these relationships were analysed in separate regression models that always retained sex, age and height as covariates (basic model). The association between PA and abdominal fat content was analyzed stratifying by CRF level (low/high). For the main analyses, we used SPSS 17.0 software for Windows (SPSS Inc, Chicago, Illinois) and the significance level was set at $5 \%$. Power analyses were performed using the PASS (Power Analysis and Sample Size) software, version 08.0.13 [9], which is based on Cohen's equations [3].

\section{Results}

$\nabla$

- Table 1 shows the association of PA with waist circumference and waist-to-height ratio by CRF levels. Vigorous PA was inversely associated with waist circumference and with waist-to-height

Table 1 Associations of objectively measured physical activity (PA) with waist circumference and waist-to-height ratio in adolescents, stratifying by cardiorespiratory fitness (CRF) level $(n=254)$.

\begin{tabular}{|c|c|c|c|c|c|c|c|}
\hline & & \multicolumn{6}{|c|}{ Abdominal fat content by anthropometry } \\
\hline & & \multicolumn{3}{|c|}{ Waist circumference } & \multicolumn{3}{|c|}{ Waist-to-height ratio } \\
\hline & & $\beta$ & $\mathbf{R}^{2}$ Change & $\mathbf{P}$ & $\beta$ & $\mathbf{R}^{2}$ Change & $\mathbf{P}$ \\
\hline \multirow[t]{4}{*}{ low CRF } & moderate PA (min day $\left.{ }^{-1}\right)^{*}$ & -0.011 & 0.001 & 0.896 & 0.011 & $<0.001$ & 0.901 \\
\hline & vigorous PA (min day $\left.{ }^{-1}\right)^{*}$ & -0.184 & 0.029 & 0.035 & -0.197 & 0.034 & 0.031 \\
\hline & MVPA (min day $\left.{ }^{-1}\right)^{\dagger}$ & -0.065 & 0.004 & 0.457 & -0.075 & 0.005 & 0.413 \\
\hline & average PA (counts/min) ${ }^{\dagger}$ & -0.127 & 0.014 & 0.146 & -0.138 & 0.017 & 0.131 \\
\hline \multirow[t]{4}{*}{ high CRF } & moderate PA (min day $\left.{ }^{-1}\right)^{*}$ & 0.011 & 0.001 & 0.864 & 0.019 & $<0.001$ & 0.787 \\
\hline & vigorous PA (min day $\left.{ }^{-1}\right)^{*}$ & -0.149 & 0.018 & 0.040 & -0.166 & 0.031 & 0.022 \\
\hline & MVPA $\left(\min \text { day }^{-1}\right)^{\dagger}$ & -0.061 & 0.003 & 0.379 & -0.065 & 0.004 & 0.378 \\
\hline & average PA (counts/min) ${ }^{\dagger}$ & -0.017 & $<0.001$ & 0.810 & -0.021 & 0.000 & 0.810 \\
\hline
\end{tabular}

In waist circumference the basic model is composed of sex, age and height

In waist-to-height ratio the basic model is composed of sex and age

$\beta$ : standardised linear regression coefficient. * Squared root transformed; ${ }^{\dagger}$ Natural logarithm transformed 
Table 2 Associations between objectively measured physical activity (PA) and abdominal fat content (R1, R2 and R3) by DXA, stratifying by cardiorespiratory fitness (CRF) level ( $n=254)$.

\begin{tabular}{|c|c|c|c|c|c|c|c|c|c|c|}
\hline & & \multicolumn{9}{|c|}{ Abdominal fat by DXA } \\
\hline & & \multicolumn{3}{|c|}{ R1 } & \multicolumn{3}{|c|}{ R2 } & \multicolumn{3}{|c|}{ R3 } \\
\hline & & $\beta$ & $R^{2}$ Change & $\mathbf{P}$ & $\beta$ & $R^{2}$ Change & $\mathbf{P}$ & $\beta$ & $R^{2}$ Change & $\mathbf{P}$ \\
\hline \multirow[t]{4}{*}{ low CRF } & moderate PA (min day $\left.{ }^{-1}\right)^{*}$ & -0.074 & 0.005 & 0.397 & -0.065 & 0.004 & 0.464 & -0.045 & 0.002 & 0.611 \\
\hline & vigorous $\mathrm{PA}\left(\min \text { day }^{-1}\right)^{*}$ & -0.278 & 0.067 & 0.002 & -0.302 & 0.079 & 0.001 & -0.249 & 0.045 & 0.005 \\
\hline & MVPA (min day $\left.{ }^{-1}\right)^{\dagger}$ & -0.178 & 0.028 & 0.044 & -0.183 & 0.029 & 0.042 & -0.146 & 0.019 & 0.105 \\
\hline & average PA (counts/min) ${ }^{\dagger}$ & -0.235 & 0.048 & 0.007 & -0.244 & 0.052 & 0.006 & -0.196 & 0.034 & 0.029 \\
\hline \multirow[t]{4}{*}{ high CRF } & moderate PA (min day $\left.{ }^{-1}\right)^{*}$ & -0.065 & 0.004 & 0.319 & -0.078 & 0.006 & 0.244 & -0.078 & 0.006 & 0.249 \\
\hline & vigorous $\mathrm{PA}\left(\min \text { day }^{-1}\right)^{*}$ & -0.221 & 0.040 & 0.002 & -0.223 & 0.040 & 0.002 & -0.221 & 0.040 & 0.003 \\
\hline & MVPA (min day $\left.{ }^{-1}\right)^{\dagger}$ & -0.150 & 0.020 & 0.027 & -0.160 & 0.023 & 0.022 & -0.159 & 0.023 & 0.024 \\
\hline & average PA (counts/min) ${ }^{\dagger}$ & -0.090 & 0.007 & 0.193 & -0.098 & 0.008 & 0.166 & -0.096 & 0.008 & 0.179 \\
\hline
\end{tabular}

$\beta$ : standardised linear regression coefficient. * Squared root transformed; ' Natural logarithm transformed; DXA: dual energy x-ray absorptiometry; R1 includes a body area from top of the iliac crest to the end of the lowest rib; R2 includes from top of the iliac crest to the junction of the T12 and L1 vertebrae; R3 includes from top of the iliac crest to the costobertebrae articulation of the last rib

Basic model: adjusted by sex, age and height

ratio to a similar extent in both low and high CRF levels $(\beta$ ranged from -0.149 to -0.197 ; $\mathrm{p}$ from 0.022 to 0.040 ). 0 Table 2 shows the associations between PA and abdominal fat content assessed using DXA (R1, R2 and R3) by CRF levels. In adolescents with low CRF, vigorous PA ( $\beta$ ranged from -0.249 to -0.302 ; $p$ from 0.001 to 0.005 ) and average PA ( $\beta$ ranged from -0.196 to $-0.244 ; p$ from 0.006 to 0.029 ) were inversely associated with abdominal fat content. Similar results were found for MVPA with R1 and R2 ( $\beta$ from -0.178 to $-0.183 ; p$ from 0.042 to 0.044 ). In adolescents with high CRF level, vigorous PA ( $\beta$ ranged from -0.221 to -0.223 ; $p$ from 0.002 to 0.003 ) and MVPA ( $\beta$ from -0.150 to -0.160 ; $\mathrm{p}$ from 0.022 to 0.027 ) were inversely associated with abdominal fat content. This association did not significantly differ according to CRF group ( $\mathrm{p}$ for interaction $>0.05$ ), yet, the percentage of variance in abdominal fat content, when assessed by DXA, explained by PA was slightly higher in adolescents with low CRF (3-8\%) compared to those with high CRF (2-4\%). For vigorous $\mathrm{PA}$ the percentage of variance explained ranged from $\sim 5-8 \%$ in low CRF, while it was $4 \%$ in high CRF adolescents. For average PA the percentage of variance explained ranged from $\sim 3-5 \%$ in low CRF, while it was $\sim 0.1 \%$ in high CRF adolescents. The results did not change when the analyses were repeated using the age- and gender-specific median to dichotomise the CRF level, instead of the FITNESSGRAM cut offs.

\section{Discussion}

$\nabla$

Cardiorespiratory fitness has shown to be an interacting factor in the relationships between PA and some health outcomes, e.g. metabolic risk factors [7]. Cardiorespiratory fitness has an important genetic component [1], however PA is the main determinant. People genetically predisposed towards having a better fitness level may also be predisposed towards having a lower fat content, thus PA being less influential. The main hypothesis tested in this study was that the association between PA and abdominal fat would be stronger in the group of adolescents with low CRF compared to that in the group of high CRF. We observed that despite the percentage of variance in abdominal fat explained by PA was slightly greater in the low CRF group, no significant $\mathrm{CRF} \times \mathrm{PA}$ interaction was found and the differences observed cannot be considered meaningful. The findings observed in this study do not therefore support the working hypothesis. In a previous study we observed paradoxical findings since vigorous PA was positively associated with abdominal fat content in children and adolescents with high CRF level [21], which do not concur with the present results.

It is important to consider when interpreting these findings that due to the study design (cross-sectional) it is not possible to infer a causal relationship between PA and body fatness. Although we controlled for several potential confounders we cannot be certain that other unmeasured confounders, such as dietary intake and genetic variation, did not influence the observations. It is also noteworthy that the accelerometers do not compensate for the relative increase in energy expenditure by increase in body size and non-weight bearing activities such as swimming or cycling are not properly measured by the accelerometers. Despite the limitations highlighted above, accelerometry has proven to correlate reasonably with doubly labelled waterderived energy expenditure [25], and is considered nowadays a method of choice for objectively measuring PA in everyday life of children and adolescents.

DXA data were available only in a sub-sample of the HELENA study. As we failed to find a significant CRF $\times$ PA interaction in relation to abdominal fatness in the present study, considerations about statistical power and type-II error need to be discussed. We performed power analyses on the multiple regression models presented in this study. For a level of significance of 0.05 , with the current sample size, taking into account the R-squared of all the covariates in the model, the number of covariates, and the R-squared added by the interaction term, we observed a power of $40-45 \%$ for the main models. The low power observed should be considered a limitation of this study. For exploratory purposes, we made power calculations repeating the same models but using waist circumference from the whole HELENA study sample (i.e., $>2000$ participants) and the statistical power increased to $\sim 95 \%$. The results for waist circumference using the whole HELENA sample are similar to the ones using the DXA sub-sample (data not shown). This finding suggests that the current results are not likely to differ substantially by increasing the sample size. In addition, the lack of interaction by sex or age suggests that the associations observed in this study are consistent for adolescents of different age, and for boys and girls. The absence of differences among boys and girls in the association between PA and abdominal adiposity has been reported elsewhere [21], and that partially supports our results. The use of 
sophisticated methods such as accelerometers and also DXA are notable strengths of our study.

In conclusion, the results indicate that there is not a clear interaction effect of CRF in the association between PA and abdominal fat in adolescents, yet slightly stronger association was observed in the low fit group. The lack of significant interactions suggests that adolescents with either higher or lower CRF levels are similarly susceptible to being positively influenced by PA. Further research is warranted.

\section{Acknowledgments}

$\nabla$

"The HELENA study takes place with the financial support of the European Community Sixth RTD Framework Programme (Contract FOOD-CT-2005-007034). This study is also being supported by grants from the Spanish Ministry of Education (EX-20080641, AP2005-4358), the Swedish Heart-Lung Foundation (20090635), the Swedish Council for Working Life and Social Research, and the ALPHA study, a European Union-funded study, in the framework of the Public Health Programme (Ref: 2006120), and the Spanish Ministry of Health: Maternal, Child Health and Development Network (number RD08/0072). The content of this article reflects only the authors' views, and the European Community is not liable for any use that may be made of the information contained therein."

\section{Affiliations}

Department of Medical Physiology, School of Medicine, University of Granada, Granada, Spain.

Unit for Preventive Nutrition, Department of Biosciences and Nutrition at NOVUM, Karolinska Institutet, Huddinge, Sweden.

Exercise Science Laboratory, Northern Michigan University, Marquette, MI, USA

${ }^{4}$ Immunonutrition Research Group, Department of Metabolism and Nutrition, Institute of Food Science, Technology and Nutrition (ICTAN), Spanish National Research Council (CSIC), Madrid, Spain.

5 a GENUD “Growth, Exercise, NUtrition and Development” Research Group. Universidad de Zaragoza, Spain. ${ }^{b}$ Faculty of Health and Sport Science (FCSD), Department of Physiotherapy and Nursing. Universidad de Zaragoza, Huesca, Spain. 'School of Health Science (EUCS), Universidad de Zaragoza, Zaragoza, Spain.

${ }^{6}$ INRAN: National Research Institute for Food and Nutrition. Rome, Italy. Department of Pediatrics and Adolescents Medicine, Division of Nutrition and Prevention Medical University of Vienna. Vienna, Austria

\section{References}

1 Bouchard C, Rankinen T. Individual differences in response to regular physical activity. Med Sci Sports Exerc 2001; 33: S446-S451 discussion S452-S443

2 Brambilla P, Bedogni G, Moreno LA, Goran MI, Gutin B, Fox KR, Peters $D M$, Barbeau P, De Simone M, Pietrobelli A. Crossvalidation of anthropometry against magnetic resonance imaging for the assessment of visceral and subcutaneous adipose tissue in children. Int J Obes (Lond) 2006; 30: 23-30

3 Cohen J. Statistical Power Analysis for the Behavioral Sciences, Lawrence Erlbaum Associates. Hillsdale, New Jersey; 1988

4 Cureton KJ, Warren GL. Criterion-referenced standards for youth health-related fitness tests: a tutorial. Res Q Exerc Sport 1990; 61: 7-19

5 Dencker M, Thorsson O, Karlsson MK, Linden C, Wollmer P, Andersen LB. Daily physical activity related to aerobic fitness and body fat in an urban sample of children. Scand J Med Sci Sports 2008; 18: 728-735

6 Ekelund U, Anderssen SA, Froberg K, Sardinha LB, Andersen LB, Brage S. Independent associations of physical activity and cardiorespiratory fitness with metabolic risk factors in children: the European youth heart study. Diabetologia 2007; 50: 1832-1840

7 Franks PW, Ekelund U, Brage S, Wong MY, Wareham NJ. Does the association of habitual physical activity with the metabolic syndrome differ by level of cardiorespiratory fitness? Diabetes Care 2004; 27: 1187-1193
8 Harriss DJ, Atkinson G. International Journal of Sports Medicine - Ethical Standards in Sport and Exercise Science Research. Int J Sports Med 2009; 30: 701-702

9 Hintze J. PASS (Power Analysis and Sample Size, version 08.0.13). 2008 NCSS, LLC Haysville, Utah; 2008; www.ncss.com

10 Janssen I, Katzmarzyk PT, Srinivasan SR, Chen W, Malina RM, Bouchard $C$, Berenson GS. Combined influence of body mass index and waist circumference on coronary artery disease risk factors among children and adolescents. Pediatrics 2005; 115: 1623-1630

11 Kamel EG, McNeill G, Van Wijk MC. Usefulness of anthropometry and DXA in predicting intra-abdominal fat in obese men and women. Obes Res 2000; 8: 36-42

$12 \mathrm{Kim}$ Y, Lee $S$. Physical activity and abdominal obesity in youth. Appl Physiol Nutr Metab 2009; 34: 571-581

13 Leger LA, Mercier D, Gadoury C, Lambert J. The multistage $20 \mathrm{~m}$ shuttle run test for aerobic fitness. J Sports Sci 1988; 6: 93-101

14 Lloyd-Jones D, Adams R, Carnethon M, De Simone G, Ferguson TB, Flegal $K$, Ford E, Furie K, Go A, Greenlund $K$, Haase $N$, Hailpern $S$, Ho M, Howard $V$, Kissela B, Kittner S, Lackland D, Lisabeth L, Marelli A, McDermott M, Meigs J, Mozaffarian D, Nichol G, O'Donnell C, Roger V, Rosamond W, Sacco R, Sorlie P, Stafford R, Steinberger J, Thom T, Wasserthiel-Smoller $S$, Wong N, Wylie-Rosett J, Hong Y. Heart disease and stroke statistics - 2009 update: a report from the American Heart Association Statistics Committee and Stroke Statistics Subcommittee. Circulation 2009; 119: 480-486

15 Moliner-Urdiales D, Ruiz JR, Vicente-Rodriguez G, Ortega FB, Rey-Lopez $J P$, Espana-Romero V, Casajus JA, Molnar D, Widhalm K, Dallongeville J, Gonzalez-Gross M, Castillo MJ, Sjostrom M, Moreno LA. Associations of muscular and cardiorespiratory fitness with total and central body fat in adolescents; The HELENA Study. Br J Sports Med 2009

16 Moreno LA, De Henauw S, Gonzalez-Gross M, Kersting M, Molnar D, Gottrand F, Barrios L, Sjostrom M, Manios Y, Gilbert CC, Leclercq C, Widhalm K, Kafatos A, Marcos A. Design and implementation of the Healthy Lifestyle in Europe by Nutrition in Adolescence Cross-Sectional Study. Int J Obes (Lond) 2008; 32 (Suppl. 5): S4-S11

17 Nagy E, Vicente-Rodriguez G, Manios Y, Beghin L, Iliescu C, Censi L, Dietrich S, Ortega FB, De Vriendt T, Plada M, Moreno LA, Molnar D. Harmonization process and reliability assessment of anthropometric measurements in a multicenter study in adolescents. Int J Obes (Lond) 2008; 32 (Suppl 5): S58-S65

18 Nilsson A, Anderssen SA, Andersen LB, Froberg $K$, Riddoch C, Sardinha $L B$, Ekelund $U$. Between- and within-day variability in physical activity and inactivity in 9- and 15-year-old European children. Scand J Med Sci Sports 2009; 19: 10-18

19 Ortega FB, Artero EG, Ruiz JR, Espana-Romero V, Jimenez-Pavon D, Vicente-Rodriguez G, Moreno LA, Manios Y, Beghin L, Ottevaere C, Ciarapica $D$, Sarri K, Dietrich S, Blair SN, Kersting M, Molnar D, Gonzalez-Gross M, Gutierrez A, Sjostrom M, Castillo MJ. Physical fitness levels among European adolescents: The HELENA study. Br J Sports Med 2010

20 Ortega FB, Artero EG, Ruiz JR, Vicente-Rodriguez G, Bergman P, Hagstromer M, Ottevaere C, Nagy E, Konsta O, Rey-Lopez JP, Polito A, Dietrich S, Plada M, Beghin L, Manios Y, Sjostrom M, Castillo MJ. Reliability of health-related physical fitness tests in European adolescents. The HELENA Study. Int J Obes (Lond) 2008; 32 (Suppl. 5): S49-S57

21 Ortega FB, Ruiz JR, Hurtig-Wennlof A, Vicente-Rodriguez G, Rizzo NS, Castillo MJ, Sjostrom M. Cardiovascular fitness modifies the associations between physical activity and abdominal adiposity in children and adolescents. The European Youth Heart Study. Br J Sports Med 2010; 44: 256-262

22 Ortega FB, Ruiz JR, Sjostrom M. Physical activity, overweight and central adiposity in Swedish children and adolescents: the European Youth Heart Study. Int J Behav Nutr Phys Act 2007; 4: 61

23 Ortega FB, Ruiz JR, Vicente-Rodriguez G, Sjostrom M. Central adiposity in 9- and 15-year-old Swedish children from the European Youth Heart Study. Int J Pediatr Obes 2008; 3: 212-216

24 Ortega FB, Tresaco B, Ruiz JR, Moreno LA, Martin-Matillas M, Mesa JL, Warnberg J, Bueno M, Tercedor P, Gutierrez A, Castillo MJ. Cardiorespiratory fitness and sedentary activities are associated with adiposity in adolescents. Obesity (Silver Spring) 2007; 15: 1589-1599

25 Plasqui G, Westerterp KR. Physical activity assessment with accelerometers: an evaluation against doubly labeled water. Obesity (Silver Spring) 2007; 15: 2371-2379

26 The Cooper Institute. FITNESSGRAM Test Administration Manual. $3^{\text {rd }}$ ed., Champaign, IL: Human Kinetics; 2004 